Rev. Chll. Pedlatr. 65 (4); 205-209, 1994

\title{
Meningitis bacteriana recurrente
}

\author{
Ana Chávez P. ${ }^{\text {; }}$ Daniel Bahamondes E. 2 ; \\ Perla David G. ${ }^{3}$; Ana María Contador I. ${ }^{4}$
}

\section{Recurrent bacterial meningitis}

\begin{abstract}
Clinical records of 524 children admitted along a ten year period, from jonuary 1983 throughour december 1992 , to a university associaled putlic children's hospital ot soulhern metropolitan Sontiago. Chile, with acule bacterial meningilis, were reviewed to search those patienls that suffered some recurrence of the disease. Eleven such potients $(2.0 \% \%$, were thus identified and prospectively recalled lor clinical, radiological, ullrasonographic, scintigraphic and inmundogical reevaluation. A predisposing laclor for recuntence was detected in nine of ten patients that came bock to recall: on obnomal humoral or cellular inmmune response in four, congenital cerebrospinal fluid fislutae in two, and Iraumatic listuloe in three cases. Recurrences may be prevented in these palients by careful history taking ond physicol examinalion, looking for predisposing or conditioning lactors at the first meningeal infection in every affected child. When more than one meninged infection has occured to a given infanil or children, early systemalic elinical and laboratory investigation of polentiol causes, pauticularly neurosurgical, otorhynological and immunological condilions is mandatory.
\end{abstract}

(Key words: meningitis, bacterial, recurrent, cerebrospinal rhinortheo, fislula.)

La meningitis bacteriana recurrente es una entidad clínica poco conocida por su baja frecuencia, lo que muchas veces hace que el estudio de los pacientes afectados sea incompleto. La reaparición de signos y sintomas de meningitis bacteriana después de la esterilización del líquido cefalorraquídeo (LCR) es una complicación rara, que puede ocurrir durante o después del término del tratamiento, constituyendo una de tres entidades clínicas cuya patogenia e implicancias clinicas son distintas: recurrencia, reactivación y recaída.

La reactivación es la reaparición, durante cl tratamiento, de signos clínicos y de laboratorio de infección meníngea, después de haberse conseguido inicialmente respuesta clínica satisfactoria y esterilización de $\mathrm{LCR}^{\mathrm{l-5}}$. La recaída es

1. Unidad de Infecciosos. Hospital Exequiel González Cortés.

2. Becado. Servicio de Pediaría. Hospital Exequiel González Contes. Deparamento de Pediatría Sur. Facultad de Medicina, Universidad de Chile.

3. Lnidad de Neurología. Hospital Excquiel González Conés.

4. Servicio de Otorrinolaringología. Hospital Barros Luco Trudeau. la reaparición de signos clínicos y de laboratorio de meningitis en las tres o cuatro semanas siguientes al término del tratamiento de la cnfermedad inicial, causada por el mismo agen$t^{1-4}$. La recurrencia es un nuevo episodio de meningitis bacteriana, después del período de convalecencia de la afección original, debido a reinfección con la misma o diferente especie bacteriana y no por persistencia de la infección inicial.

Se han identificado diversos factores condicionantes o predisponentes a la meningitis recurrente, como los defectos de la inmunidad humoral y celular; las comunicaciones anatómicas congénitas, que incluyen senos dermoides, epidermoides, defectos rinosinusales (en la placa cribiforme del eumoides, los senos frontales o el techo esfenoidal), defectos otológicos (en la ventana oval, cl conducto auditivo extemo o el acueducto coclear), así como también comunicaciones ađquiridas por traumatismos rinosinusales u otológjcos. Ambos tipos de defectos estructurales establecen soluciones de continuidad cntre el espacio subaracnoideo y las cavidades paranasales, del oído medio, la rinofaringe o la superficie de la piel $^{1,2,6-9}$. 
Pucsto que las publicaciones sobre el problema son escasas, la mayoría referidas a casos es pecíficos o aislados, se realizó este estudio con los propósitos de describir la frecuencia de éste en pacientes que fueron admitidos a lo largo de un período de diez años en un hospital base de un servicio metropolitano de salud (enero de 1983 a diciembre de 1992); evaluar a los pacientes afectados desde el punto de vista neurológico, otorrinológico e inmunológico, tratando de identificar los factores condicionantes de la recurrencia y su posible tratamiento y formular las bases para un protocolo de estudio de estos enfermos.

\section{Material y Método}

Se revisason las fichas clínicas de todos los pacientes que egresaron del Hospital Exequiel González Cortés, del Servicio de Salud Metropolitano Sur de Sanijago, Chile, con diagnóstico de meningitis bacteriana aguda, desde el 1 de enero de 1983 hasta el 31 de diciembre de 1992, seleccionando aquellos que correspondian a meningitis rccurrente, definida ésıa como aquella enfermedad en que se comprueba un nuevo episodio de meningitis, después de transcurridos 2 l días desde el término del tratamiento de otro precedente.

Los pacientes seleccionados fueron ciladios a ta unidad de enfermedades infecciosas del hospital aludido, donde -a cada uno de cllos- se rcalizó examen clínico general; una evaluación ncurológica, consistente en examen clínico, electroencefalograma, tomogra ${ }_{i ́ a}$ axial computadorizada del cerebro y la fosa posterior (en algunos niños se realizó, ademśs, examen psicométrico, gamacnecfalografía, radiocistemografía isotópica y resonancia nuclear magnética. según fuese necesario); evaluación otorrinológica mediante examen clínico, audiometría o polenciales evocados auditivos, radiografía de cavidades paranasales y tomografía axial computadorizada de pet̃asco y cavidades paranasales; evaluación inmunológica clínica, recuento de linfocitos: medición de inmunoglobulinas, $\mathrm{C}_{3}$ y $\mathrm{C}^{\prime} \mathrm{H}_{50}$ séricos, reaccjón intradémica a PPD; quimiotaxis y fagocitosis de los leucocitos y -en un pacienle que asi lo requería- pneba cutánea múltiple para hipersensibilidad retardada.

\section{Resultados}

En el período señalado se registraron los ingresos de 524 niños con diagnóstico de meningilis bacteriana aguda en el hospital del estudio, Il $(2,09 \%)$ de los cuales (seis mujeres) sufricron a lo menos una recurrencia. En el primer episodio tres pacientes tenían menos de un año de cdad, dos entre uno y menos de dos af̂os (lactantes mayores), tres entre dos y menos de cinco años (prcescolares) y tres cinco o más años de edad (escolares), con márgenes de 4 meses a 13 años y 6 meses. Ocho pacientes sufrieron una recurrencia; los restantes tres enfermos tuvieron dos recurrencias cada uno, de modo que el total dc episodios observados de meningitis bacteriana agruda fue 25 en estos 11 casos.

El intervalo de ticmpo transcurrido entre el primer. y segundo episodio varió entre uno y 24 meses (menos de 6 meses en 8 casos). Entrc el segundo y el tercero, cuando éste se registró, fue entre uno y dos mescs. En 16 de los 25 episodios se pudo aislar el agente bacteriano causante: Streptococcus pneumoniae $(\mathrm{n}=7)$, Haemophilus influenzae tipo b $(\mathrm{n}=4)$, Haemophilus $s p(\mathrm{n}=2)$, Neisseria meningitidis grupo $\mathrm{B}(\mathrm{n}=2)$, Escherichia coli $(\mathrm{n}=1)$. En las otras nueve no se identificaron bacterias responsables.

La evaluación y csludio adicionales se cumplicron en diez de los once pacientes, ya que no fue posible ubicar a uno de ellos. En el momento de hacerla, dos niños eran lactantes mayores, tres preescolares y cinco escolares.

En nucve casos se pesquisó un factor que podía ser considerado condicionante de la recuIrencia. En cuatro pacientos se trataba de un defecto de la inmunidad (dos tenían déficit en la quimiolaxis, uno trastorno combinado de inmunidad humoral y cclular y otro una combinación de déficit de quimiotaxis y de inmunidad celular). En dos niños se detectố una fístula congénita de líquido cefalorraquídeo: en uno se sospechó la fístula congénita por que tenía microftalmia, asimctría facial ósea y rinorrea intermitente asociada a cambios de posición, confirmándose por radiología que había un defecto óseo en la lámina cribosa del emoides. La segunda paciente con fístula congénita tenía un seno dérmico en la región occipital; la resonancia nuclear magnética constató la presencia de un quiste a nivel cerebeloso y la niña falleció, demostrándose en la necropsia que la lesión correspondía a un quistc dermoide abscedado.

En tres pacientes había fístulas de origen traumático. Los tres eran escolares y tenian antecedentes de traumatismo encefalocraneano. Uno había requerido de cirugía para corrección de la órbita, lo que podria explicar la existencia de la fístula. En otro se buscó infructuosamente la fístula en dos oportunidades (precozmente en relación a una fractura frontal izquierda con ocupación de seno, después del primer episodio de 
meningitis) para comprobarla sólo luego del segundo episodio de meningitis. Este paciente se sometió a corrección quirúrgica y actualmente sc encuentra asintomático. El tercero tenía antecedentes de traumatismo encefalocraneano cerrado con estudio neurorradiológico previo negativo: después del segundo episodio de meningitis se buscó una fístula, que se comprobó mediante tomografía axial, la que reveló una fractura frontoórbito-etmoidal derecha. El intervalo de tiempo entre el traumatismo y el primer episodio de meningitis varió entre los 16 y 27 meses. Sólo en un paciente no se consiguió identificar un factor condicionante.

Se intentó establecer una correlación entre factor predisponente, grupo etario y agente etiológico. Los cuatro pacientes en que se demostró un defecto inmunológico eran lactantes menores. Los gérmenes aislados en ellos fueron, respectivamente en cada caso, Haemophilus influenzae tipo b, $H$. influenzae no tipificado, Streptococcus pneumoniae y Neisseria meningitidis tipo B, repitiéndose en todos los casos el mismo agente en los dos episodios. Los niños con fístula con. génita de líquido cefalorraquídeo, un lactante mayor y un preescolar, sufrieron dos recurrencias (tres episodios) cada uno, pero sólo en uno se identificaron agentes bacterianos: Haemophilus influenzae no tipificado en la primera infección y Escherichia coli en la segunda. Los tres pacientes con fístulas traumáticas del liquido cefalorraquideo eran escolares, todos tenían antecedentes de traumalismo encefalocraneano y cada uno sufrió una recurrencia: en uno cllos se aisló el agente causal de ambos episodios, en otro sólo de la recurrencia y en el tercero de ninguna de las dos infecciones, pero en todos los casos positivos se trataba de Streptococcus pneumoniae.

De los diez pacientes evaluados, cuatro se encuentran actualmente en control en inmunología; a un escolar se le realizó cierre quirúrgico de su fístula traumática y los otros tres pacientes con fístulas (dos traumáticas y una congénita) se encuentran en espera de tratamicnto neuroquirúrgico. Una lactante mayor falleció durante la evolución de la segunda recurrencia de meningitis, mientras esperaba por la corrección quirúrgica de un defecto anatómico congénito. Por último, un preescolar en el que no se logró detectar factor condicionante se mantiene en control y es reevaluado periodicamente.

\section{Comentario}

Cada episodio de meningitis bacteriana aguda representa una enfermedad grave ${ }^{10.11}$ y su recurrencia obliga a realizar un estudio cxhaustivo y multidisciplinario, tendiente a identificar la causa de ésta, ya que en muchos casos es susceptible de corrección, evitando que la infección meníngea se produzca nuevamente. En todos los pacientes con meningitis bacteriana aguda se debe investigar, en el primer episodio, la existencia de algún factor predisponente de eventuales recurrencias, indagando mediante la anamnesis antecedentes de traumatismo encefalocraneano ${ }^{6,8,15}$, procesos otorrinológicos ${ }^{6,12 \cdot 14} u$ otras infecciones severas que hagan sospechar una alteración de la inmunidad. En el examen físico se deben buscar cuidadosamente lesiones dérmicas (senos dermoides) u óseas, que sugieran asociación con defectos anatómicos del sistema nervioso central $1,2,7$.

En la serie que se comenta, la primera recurrencia ocurrió antes de seis meses de la infección inicial en la mayoría de los casos, por lo que el estudio adicional de estos pacientes debiera ser muy precoz. Lamentablemente, éste requiere la concurrencia de varios especialistas y exámenes complejos y caros, a los que nuestros pacientes acceden con dificultad, impidiendo muchas veces diagnosticar oportunamente la causa de la reiteración de la afección.

En nuestros pacicntes se registró cierta relación entre los factores predisponentes y la edad, pues en los lactantes se comprobaron con frecuencia defectos de la inmunidad y cn los escolares fístulas traumáticas. La ausencia de afecciones otológicas como condición precipitante de meningitis recurrente en ellos concuerda con otras descripciones en que también resultaron infrecuentes ${ }^{12-14}$. Cuando estas últimas han sido detectadas, consisten en defectos anatómicos del oído interno y medio que comunican con el espacio subarac. noideo, pueden manifestarse por hipoacusia y se comprucban mediante tomografia axial computadorizada del peñasco $0^{1,2,8}$.

La manifestación más frecuente de las fístulas de liquido cefalorraquídeo es la ninorrea ${ }^{8 .}{ }^{19}$, debido al gran número de sitios potenciales de anomalías de la fosa frontal basal ${ }^{20}$. Los defectos congénitos del piso de la base craneana anterior se ubican, en la mayoria de los casos de niños, en la lámina cribosa del etmoides ${ }^{8,15,21}$. Las co- 
municaciones congénilas con el líquido celalorraquídeo pueden tener relación con defectos óseos faciales o de todo lo largo de la línca media corporal -desde el cráneo hasta el cóccixpudiendo terminar en quistes dermoides intradurales o cn tumores ubicados entre la fosa posterior hasta la cola de caballo7. 8, 13, 20. 21. E] método de elección en estos casos, para confirmar el defecto, es la resonancia nuclear magnética ${ }^{8}$.

Las fístulas traumáticas se describen aun ante traumatismos mínimos y remotos ${ }^{19.22}$, siendo de difícil detección, ya que la rinorragia es un signo poco relevante para el paciente, su curso intermitente hace dificil pesquisarlas clínicamente y un estudio de radiológico negativo no las descarta, como lo ilustran nuestros pacientes ${ }^{22}$.

Independiente del origen de la fístula, congénita o adquirida, el tratamiento es sicmpre quirúrgico $0^{8,9,15,21}$ y consiste en cerrar la brecha ósea y la apertura meníngea y reconstituir el seno comprometido, en caso necesario. Algunos pacientes requieren varias intervenciones antes de conseguir el cierre de la fístula, obteniéndose cn los mejores centros hasta $63 \%$ de éxito ${ }^{8,21}$.

Los tres niños en que se comprobó un defecto de la inmunidad eran lactantes, no existicndo en ninguno de cllos el antecedente de infeccioncs severas que hicieran sospechar el trastorno básico, a diferencia de lo descrito en la literatura ${ }^{16-18,23}$.

La falta de confírmación de defectos anatómicos o de la inmunidad no descarta la existencia de algún factor predisponęnte de meningitis recurrente ${ }^{19}$, razón por la cual los paciente con infecciones meningeas reiteradas, en que la búsqueda de ellas resulta negativa, deben ser sujetos a reevaluaciones periódicas. Ante las dificultades, por la trascendencia y el alto coste implicados en el diagnóstico patogénico en estos pacientes, conviene seguir un protocolo organizado cn su estudio, que incluya investigar, en cualquicr primer episodio de meningitis bacteriana aguda, factores predisponentes de recurrencias, como antecedentes de traumatismo encefalocrancano, procesos otorrinológicos, infecciones severas repetidas y lesiones dérmicas u óseas que sugieran defectos anatómicos del sistema nervioso. Cuando se trata de pacientes con más de un episodio de meningilis, es preciso realizar evaluaciones neurológica, otorrinológica e inmunoló- gica -clínicas e instrumentales-, por los correspondientes especialistas; radiografías de cráneo y cavidades paranasales, planigrafía local; tomografías axiales del cerebro, fosa posterior, pe. ñasco y cavidades paranasales (cuando los antecedentes lo justifican, radiocistemografía isotópica y resonancia nuclear magnética); audiometría o potenciales evocados auditivos; re. cuento de linfocitos, pruebas de quimiotaxis y fagocitosis, cuantificación de inmunoglobulinas, $\mathrm{C}_{3}$ y $\mathrm{C}^{\prime} \mathrm{H}_{50}$ en el suero y reacción cutánea al PPD.

\section{Resumen}

Se revisaron retrospectivamente 524 registros clínicos de pacientes que ingresaron a un hospital metropolitano de Santiago por meningitis bacteriana aguda entre enero de 1983 y diciembre de 1992, con el objeto de identificar a los que sufricron meningitis aguda bacteriana recurrente, describir la proporción de casos en que ésta curre y las causas o factores predisponentes o condicionantes del fenómeno. Se identificaron once pacientes $(2,09 \%$ dc los ingresados por meningitis aguda bacteriana) con una o más recutrencias y 25 episodios en total. Todos los afeclados fueron citados para evaluarles prospectivamente con exámenes clínicos, radiológicos y de laboratorio, con especial énfasis en los aspectos neurológico, otorrinológico e inmunológico. Un paciente no respondió al llamado, en otro la investigación realizada no permitió identificar un trastorno de base que explicase la reiteración de la infección meníngca. En los nueve restantes se cncontraron cuatro casos de defectos de la inmunidad, dos de fístulas congenitas del líquido cefalorraquídco y tres de fístulas causadas por traumatismos encefalocrancanos. Las recurrencias pueden evilarse en estos pacientes si se buscan cuidadosamente antecedentes de factores predisponentes en la historia y el examen físico de lodo niño con meningitis aguda bacteriana. La investigación, en caso de más de un episodio, debe incluir cvaluaciones neurológica, otorrinológica y de la inmunidad, empleando métodos clínicos, instrumentales (en particular de imágenes simples y contrastadas) y de laboratorio.

(Palabras clave: meningitis, bacteriana, recurrente.) 


\section{Referencias}

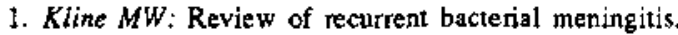
Pediatr Infect Dis J 1989: 8: 630-634.

2. Mancilla $E$, Toureda CA, Fin $M$, Andrade $G$, Redondo $G$ : Correlación entre patología otorrinolaringologica y meningitis recurrente en el niño. Revista de Otorrinolaringología y Cirugía de Cabeza y Cuetlo 1986; 46: 121. 126.

3. Schaod V.B, Nelson JD, Mc Cracken GH Jr.: Recrudescence and telapse in bacterial meningitis of chitdhhod. Pediatrics 1981: 67: 188-195

4. Puga T, Ruinsky $R$ : Meningitis bacteriana. En: Meneguello J y cols. Pediatría $3^{\star} \mathrm{ed}$. Santiago, Publicaciones Técnicas Mediterráneo. 1985; 492-502.

5. Tribiano $\mathrm{CW}$ : Four recurrent attacks of pneumococcus meningitis with recovery. J Pediatr 1953; 42: 609-611.

6. Hevia $M$. Alvarado L.M. Guerrero J, et al.: Meningitis recidivante por Streptococcus preumonize. Rev Chil Pediatr 1985; 56: 49-5I.

7. Ceccavelli M, Baiestri $M$, Fontani $C$, Lupetti L, Ughi $C$ : Recurrent meningitis: a case report. Eur J Pediatr 1989: $148: 646-647$.

8. Geoffrey $A$, Wald $S L$. Chronic or recurrent meningitis: neurosurgical perspectives. Neurosurg Clin North Am 1992: $3: 483-490$.

9. Belf WE: Baclerial meningitis in children: selected aspects. Pediatr Clin North Am 1992; 39:651-668.

10. Ovagliarello V. Scheld WM: Bacterial meningitis: pathogenesis, pathophysiology and progress. N Engl J Med 1992; 327: 864-872.

11. Commiliee on infecrious diseases: American Academy of Pediatrics. Tratamiento con dexametasona en la meningitis bacteriana en los lactantes y niños. Pediatrics (ed. esp), 1990: 30: 29-39.

12. Christensen A, Ryan Chandier $J$ : Manejo otorrinolaringológico de la fístula de líquido cefalorraquideo. Revista de Otorrinolaringología y Cirugía de Cabeza y Cuello 1978; 38: 29-38.
13. Stecle R, Connell $J$, Jacobs $R$, Mawk J: Recurrent baclerial meningitis: coronal thin section cranial compuled tomography to delineate anatomic defects. Pediatrics 1985; 76: 950-953.

14. Harris H: Cerebrospinal otornca and recurring me. ningitis: report of three cases. The Laryngoscope 1978; 88: $1577-1585$.

IS. Poblete $R$, Holzer $F$ : Fistula de líquido cefalorraquideo nasal traumática. Cinugía reparadora. Cuadernos Chilenos de Cirugía 1984; 28: 101-104.

16. Vogler LB, Newman S.L. Stroud R.M, Johnston RB: Recurrent meningococeal meningitis with absence of the sixth component of complement: an evaluation of underlying immunologic mechanisms. Pediatrics 1979; $64:$ 465-46?,

17. Peter $G$, Weigeri $B, B$ issel A, Gold $R$, Kreutzer D, MC Lean $R$ : Meningococcal meningitis in familiar deficiensy of the fifth component of complement. Pediatrics 1981; 67: 882-886.

18. Lim D, Gewurz A, Lint T, Ghaze M. Sepheri B, Gewurz II: Absence of the sixth component of complement in a patient with repeated episodes of meningococcal meningitis. J Pediatr 1976; 89: 42-47.

19. Hanley $J$, Bales J, Byrd B: Recurrent meningococcal meningitis with occult cerebrospinal fluid leak. Arch Intem Med 1979; 139: 702-703.

20. Hemphill M, Freman J, Mortinez C, Nager G, Long D. Crumrine $P$ : A new, treatable source of recurrent mening itis: basioccipital meningocele. Pediatrics 1982; $70: 941-943$.

21. Holzer F, Holzer J, Ruiz A: Fístula de líquido cefalorraquideo por fraciura de piso anterior. Revista Chilena de Neuropsiqujatía (Santiago) 1993; 31: 181-185.

22. Whitecar J, Reddin J, Spink W: Recurrent pneumocoscal meningitis. N Engl I Med 1966; 274: 1285-1289.

23. Shelanski S, Zweiman B: Recurrent Meningitis. Ann Allergy $1988 ; 60$ : 306-307 y 343-345.

\section{AVISO A LOS AUTORES}

Por acuerdo del Comité Editorial, la Revista Chilena de Pediatría devolverá sin tramitar todos los trabajos que no den estricto cumplimiento al Reglamento de Publicaciones y a las Instrucciones de los Autores que se editan en cada número de la Revista. 